\title{
Bioprospecting of microalgae metabolites against cytokine storm syndrome during COVID-19
}

\author{
Che Lah Wan Afifudeen ${ }^{2,3} \cdot$ Kit Yinn Teh ${ }^{2,3}$ (D) Thye San Cha ${ }^{1,2}$ (D)
}

Received: 28 March 2021 / Accepted: 29 October 2021 / Published online: 9 November 2021

(C) The Author(s), under exclusive licence to Springer Nature B.V. 2021

\begin{abstract}
In viral respiratory infections, disrupted pathophysiological outcomes have been attributed to hyper-activated and unresolved inflammation responses of the immune system. Integration between available drugs and natural therapeutics have reported benefits in relieving inflammation-related physiological outcomes and microalgae may be a feasible source from which to draw from against future coronavirus-infections. Microalgae represent a large and diverse source of chemically functional compounds such as carotenoids and lipids that possess various bioactivities, including anti-inflammatory properties. Therefore in this paper, some implicated pathways causing inflammation in viral respiratory infections are discussed and juxtaposed along with available research done on several microalgal metabolites. Additionally, the therapeutic properties of some known anti-inflammatory, antioxidant and immunomodulating compounds sourced from microalgae are reported for added clarity.
\end{abstract}

Keywords Acute respiratory disease syndrome $\cdot$ COVID-19 $\cdot$ Lungs infection $\cdot$ Nature therapeutics $\cdot$ SARS-CoV-2 . Symptoms suppressor

\section{Background}

Highly pathogenic viral respiratory infections such as SARS, MERS and SARS-CoV-2 (COVID-19) can cause serious repercussions on health security and threaten the economy. The most recent COVID-19 outbreak causing severe acute respiratory syndrome is a highly contagious coronavirus that has infected almost 83 million people in just 12 months. As of October 2021, the virus has affected a total of 219 countries and caused a total of 4.9 million deaths globally [1].

Thye San Cha

cha_ts@umt.edu.my

Che Lah Wan Afifudeen

wanafifudeen@gmail.com

Kit Yinn Teh

t.kityinn@gmail.com

1 Faculty of Science and Marine Environment, Universiti Malaysia Terengganu, 21030 Kuala Nerus, Terengganu, Malaysia

2 Satreps-Cosmos Laboratory, Central Laboratory Complex, Universiti Malaysia Terengganu, 21030 Kuala Nerus, Terengganu, Malaysia

3 Institute of Marine Biotechnology, Universiti Malaysia Terengganu, 21030 Kuala Nerus, Terengganu, Malaysia
Viral respiratory infections may cause severe inflammation responses in afflicted patients, driving the immune system into overdrive due to hyper-activated cytokine storm reactions [2]. Inflammation is an essential feature of the immune response and vital to human health. However, uncontrolled inflammation responses can work in the other direction if out of control. Interestingly, in the previous SARS outbreak, strategies that integrate western and traditional Chinese medicine had reported efficient remedial outcomes [3]. The pharmacokinetics of naturally sourced therapeutics such as licorice and honeysuckle have also had reported efficacy in relieving coronavirus symptoms in COVID-19 patients [3].

This opens up room to consider naturally sourced antiinflammatory therapeutics from marine sources in the cotreatment with available generic drugs. A recent de novo transcriptome study discovered genes associated with metabolism of anti-inflammatory compounds in marine diatom Cylindrotheca closterium [4] thus proving that microalgae possess inherent potential as a source for valuable antiinflammatory therapeutic compounds. As a matter of fact, microalgae indeed have interesting prospects as they represent a diverse origin of chemically functional compounds that have been studied and verified for their potential pharmaceutical and neutraceutical bioactivities. Some of the bioactivities include anti-hypertensive, anti-coagulant, 
antioxidant, anti-microbial and anti-viral properties [5]. Therefore, this review is aimed at summarizing available known anti-inflammatory, antioxidant and immune-modulating compounds from microalgae and how these compounds can potentially function in certain known afflicted viral respiratory inflammation-related pathways. The authors also discuss known clinical trials involving microalgae metabolites involving human subjects thus proving that there is basis and potential in developing anti-inflammatory therapeutics from microalgae sources.

\section{Coronaviruses and an ensuing global pandemic}

SARS, MERS and SARS-CoV-2 share many similar pathological features. The general route of infection primarily targets the lower respiratory tract of afflicted patients, often leading to acute lung injury or acute respiratory distress syndrome (ARDS), hypoxia and exacerbated cytokine responses [6]. Unlike the previous SARS global pandemic which was contained in less than a year, the severity of COVID-19 infections continue to escalate to this very day ever since it was reported on December 31st, 2019 in Wuhan, China [7]. Infected patients with SARS-CoV-2 usually experience heavy coughing, shortness of breath, high fever, ARDS and hypoxemia which is often lethal [8]. Compared to its counterpart SARS and MERS, COVID-19 is believed to possess higher transmission rates and evoke severe hyper-sensitivity symptoms such as severe inflammation leading to cytokine release syndrome $[2,6]$. In the present review, the properties of microalgae metabolites and how their associated molecular mechanisms could be useful against the pathogenesis of COVID-19 cytokine storm were discussed.

\section{Pathogenesis of SARS-CoV-2 infection during COVID-19 disease}

The SARS-CoV-2 virus travels along the trachea before arriving at the alveoli and attaches its spike proteins to type II pneumocytes thus making the lungs a susceptible site for infection and viral replication activity. Entry of SARS$\mathrm{CoV}-2$ into the intercellular environment is modulated via attachment of SARS-CoV-2 spike proteins to angiotensinconverting enzyme 2 (ACE2) receptor of type II pneumocyte (Fig. 1a and b) coupled with presence of host factor such as transmembrane protease serine 2 (TMPRSS2) [9]. Upon entry, SARS-CoV-2 releases its genetic material $(30 \mathrm{~kb}$ in length), the positive single strand RNA (+ SSRNA) and replicates using the host's RNA dependent-RNA polymerase (RdRP) and ribosomes to generate new polypeptides. Life cycle of SARS-CoV-2 heavily depends on the efficiency of viral genome replication within the host cells. This replication consists of three major steps: (1) RNA polymerization; (2) proofreading; (3) final capping. This process has been thoroughly discussed in a previous review by Romano et al. [10]. The newly assembled virus then buds off and is free to infect other pneumocyte cells in the alveoli lining (Fig. 1b).

Viral infections activate pattern-recognition receptors (PRRs) that kick-start the host's defense mechanism [2] via the: (1) innate response immunity (robust and unspecific) aimed at reducing infectivity rate of the virus, and (2) adaptive response immunity (cell-mediated and humoral responses), designed to specifically attack SARS-CoV-2 through antigen recognition mechanisms. Specialized innate immune cells then release cytokines, chemokines, interferons (IFN) and other immune-modulating mediators that generate inflammation as part of the immune response [11].

\section{Immune alteration and cytokine storm in COVID-19 patients}

Respond towards SARS-CoV-2 infection present either directly from the virus or through infected pneumocyte cells via inflammatory mediators such as histamine and serotonin (Fig. 2). Macrophages are the first to arrive on scene and are able to detect and engulf SARS-CoV-2 virus via phagocytosis [12]. Next, macrophages then prime the immune response by releasing pro-inflammatory cytokines like interleukin (IL)-1, IL-6, tumour necrosis factor alpha (TNF- $\alpha$ ) and chemokines to recruit more innate and adaptive immune cells such as macrophages, neutrophils, dendritic cells, natural killer (NK) cells and cytotoxic lymphocytes to site of infection [11]. The cytokine IL-6 has been widely attributed to SARS-CoV-2 inflammation and primarily activates cascade signalling pathways (via the Janus kinase/ signal transducer and activator of transcription (JAK/STAT3) pathway) to target transcription of multiple downstream immune-modulating and immune-stimulatory genes [13]. Sequential activation of more cytokines and chemokines initiates more inflammation vital in signalling the immune system to remove and repair damaged tissue besides viral clearance. However, in some cases, amplified secretion of pro-inflammatory cytokines can overwhelm the immune response leading to life-threatening conditions i.e. cytokine storm [14]. Although disputable, a consensus recognizes the cytokine storm, in the context of COVID-19, as the hyperactivation or auto amplifying of pro-inflammatory cytokine production. This rampant dysregulation of cytokine and chemokines leaves a trail of immunopathological damage and is closely associated with severe COVID-19 and poor prognosis in patients. Notably in SARS-CoV-2, severely ill patients were found to have high levels of both pro-inflammatory $\mathrm{CD}_{14}{ }^{+}$monocytes and chemokine receptor (CCR) 


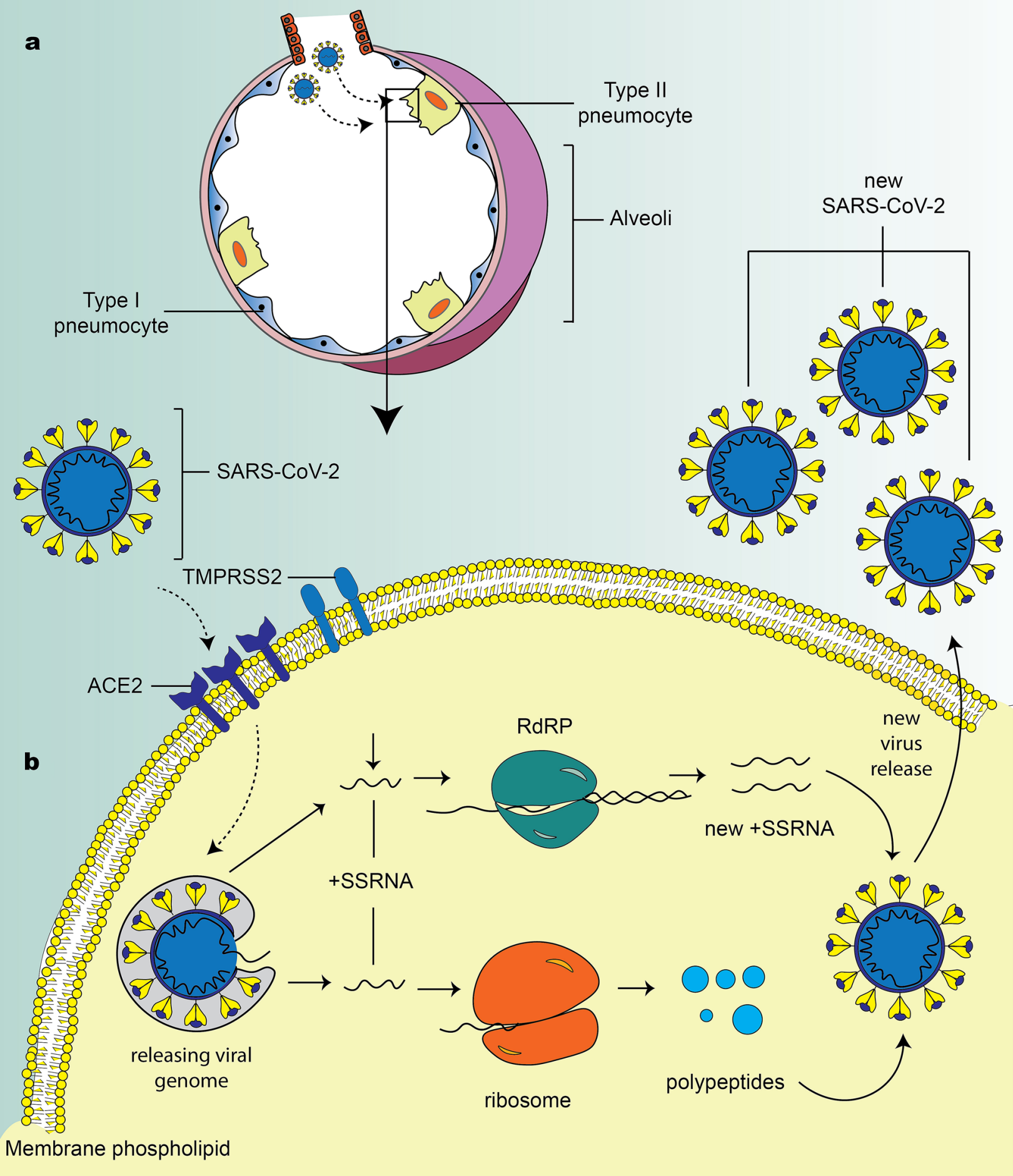

Fig. 1 Pathogenesis and viral replication mechanism of SARSCoV-2. Type II pneumocyte cells consist of angiotensin-converting enzyme 2 (ACE2) which is complementary to SARS-CoV-2 spike protein. Infection starts with attachment of SARS-CoV-2 at type II pneumocyte cells (a) in alveoli via ACE2 receptor. Upon entry, SARS-CoV-2 will release positive single stranded RNA (+ SSRNA) into intracellular environment of pneumocyte cells (b). + SSRNA will be used for viral RNA synthesis and viral polypeptides formation. Viral RNA synthesis is carried out by RNA dependent RNA polymerase (RnRP) while assembly of viral peptides is carried out by ribosome. Together (+ SSRNA and polypeptides) it will form new SARSCoV-2 virus before being transported out to extracellular environment (outside II pneumocyte cells) before spreading to other pneumocyte cells 
Fig. 2 Immune alteration and cytokine storm in alveoli during SARS-CoV-2 infection. Response to infection starts with release of inflammatory mediators from infected type II pneumocyte, this triggers the activation of macrophages and cytokine release into the blood capillaries in order to signal more leukocytes to site of SARS-CoV-2 infection. However, overwhelming effects from the release of pro-inflammatory mediators and cytokines will reduce blood capillary permeability which leads to plasma breach. Plasma breach happens when interstitial fluid which contain various leukocyte types, predominantly neutrophils, start to fill up the cavity of alveoli. The consolidation that takes place inside the cavity of alveoli leads to interstitial edema, acute respiratory distress syndrome (ARDS) and hypoxemia

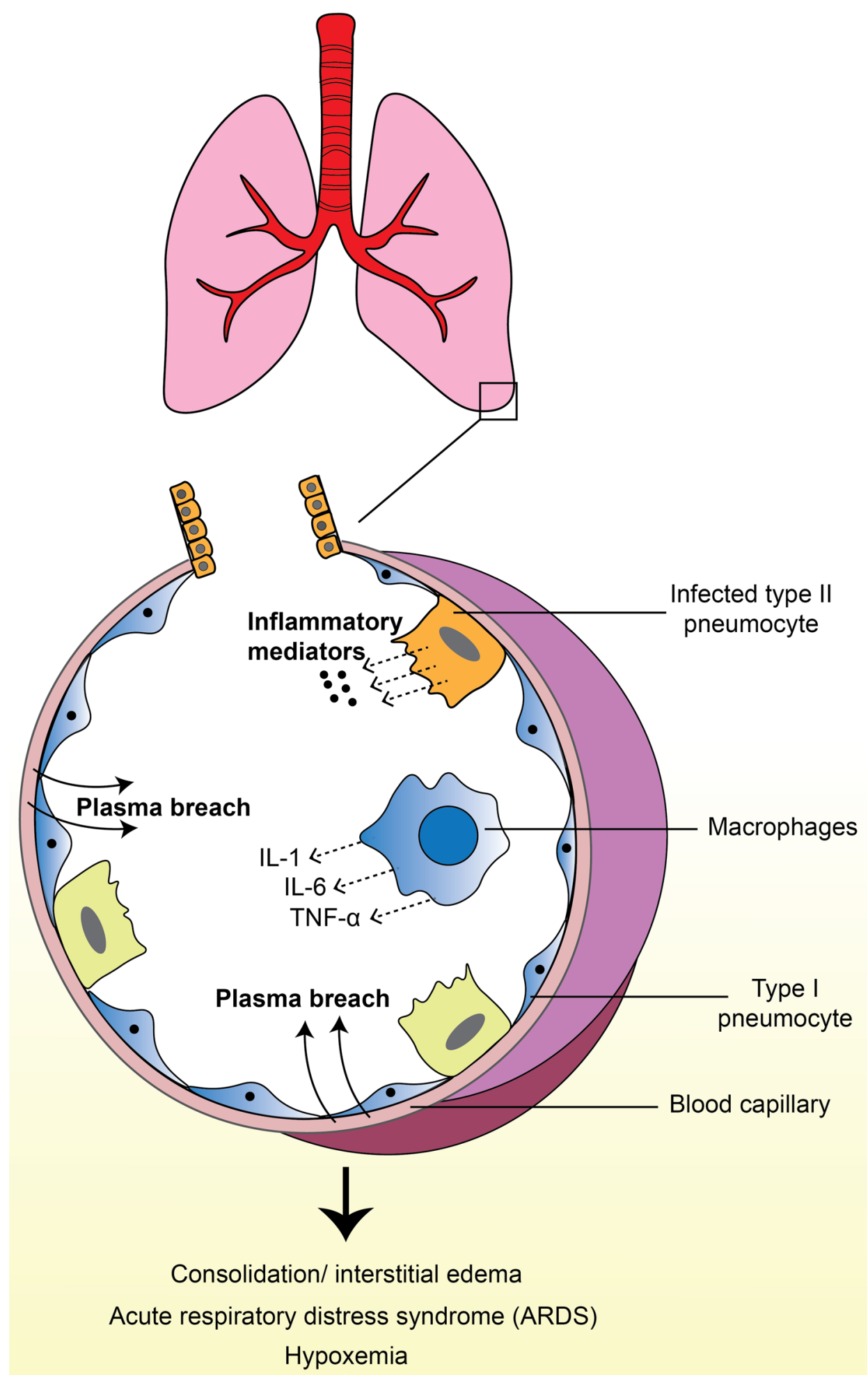

Hypoxemia
$4^{+} \mathrm{CCR}^{+}$Th17 markers that cause extreme cytokine and chemokine release, in particular IL-2, IL-6, CCL-2, CCL-3 and CXCL10 [15]. Unlike SARS, SARS-CoV-2 causes a decrease in circulating $\mathrm{CD} 4^{+}$and $\mathrm{CD}^{+}$lymphocytes, bringing on lymphopenia, a stepwise progressive loss of T-cell function, neutrophilia as well as dysregulation of monocytes and macrophages [16]. The SARS-CoV-2 virus also delayed IFN-1 responses responsible for the initiation of viral load clearance hence impeding viral clearance and inducing paradoxical hyperinflammation [16]. The resulting cytokine storm eventually leads to plasma breach characterized by interstitial fluid leak into alveoli (interstitial edema) 
to facilitate migration of leukocytes [17] (Fig. 2). Indeed, in some cases, consolidation or interstitial edema is fatal as it causes a significant reduction in gaseous exchange. This leads to hypoxemia (low level oxygen in the blood) and acute respiratory distress syndrome (ARDS) as commonly observed in COVID-19 patients [2] (Fig. 2). The occurrence of ARDS and ensuing immunopathological damage constitutes a major cause of death in COVID-19 patients. Due to its novelty, there is currently no specific drug to treat COVID-19 patients and treatment is usually administered off label via repurposing of available and experimental medicines. Evidence from ongoing clinical trials show cytokinetargeted therapies to be advantageous in the pathogenesis of severe COVID-19. In view of that, cytokine storm intervention via strategic administration of either specific or nonspecific cytokine receptor blocker drugs and anti-inflammatory agents targeting related signalling pathways in the early stages of COVID-19 infection have been suggested as a plausible approach to ensure higher survival rates [11, 15].

\section{Available drugs against COVID-19}

Drugs considered for SARS-CoV-2 treatment may work via two mechanisms: (1) reduction of replication rate of the virus and (2) suppressing symptoms via anti-inflammatory therapy. Replication of SARS-CoV-2 can be inhibited by inhibiting replication enzyme activity of RNA dependentRNA polymerase (RdRP). In January 2020, the WHO approved off-label use of remdesivir for treating COVID19 patients. Remdesivir is a drug developed to treat Ebola and has seen promising results in treatment of Middle East Respiratory Syndrome (MERS) [18]. The drug is effective in blocking RdRP by acting as a chain terminator to RdRP activity thus blocking replication of new positive single strand RNA (+ SSRNA) [19]. Alternatively, RdRP can be inhibited via zinc ionophore drugs such as chloroquine. Despite initially appearing to be promising based on its molecular activity, chloroquine caused exigent side effects of heart arrhythmia [20] and was officially banned by the WHO on June 15th 2020 [21]. An additional two other anti-viral drugs (lopinavir-ritonavir and ivermectin) had also been given consideration but had not shown to be advantageous in treating COVID-19 patients [29].

Symptoms suppressor drugs such as acetaminophen or paracetamol are also commonly employed to provide symptomatic relieve of high fever. Physiologically, elevation of pyrogenic cytokines such as IL- 1 , IL- 6 and TNF- $\alpha$ signals the endothelial cells of the hypothalamus (thermoregulatory center) and prostaglandin $\mathrm{E}_{2}$ (PGE2), [22]. This elicits peripheral heat response (high fever) in order to reduce infectivity of SARS-CoV-2. Acetaminophen is an antipyretics drug that reduces fever by reducing PGE2 production in the brain to reduce high fever [22]. However in COVID-19 patients, red flags appeared over the drug's positive correlation with ACE2 expression leading to severe side-effects in some COVID-19 cases [23].

Additionally, drugs with immunomodulating properties like Tocilizumab and Anankira work by blocking IL-6 and IL- $1 \beta$ receptors respectively [29]. The onset of cytokine storm syndrome has been linked to aberrant cytokine secretion hence the aforementioned immunomodulating drugs work as binder agents towards the soluble membrane bound IL-6/IL-1 $\beta$ receptors in order to reduce cytokine-induced inflammation [24]. However, their use in treatment of COVID-19 patients have proved to be inconclusive. At the moment, a standard immunomodulator drug used to treat COVID-19 is a corticosteroid known as dexamethasone which is usually used in combination with remdesivir [29].

The aforementioned targeted drugs are still considered as experimental drugs and used under strict surveillance due to their side effects. Other ways of treatment exploring outside the boundaries of chemical drugs include the use of therapeutics in the form of antibodies. Treating COVID-19 patients with convalescent plasma and engineered cocktail mixes of antibodies such as REGN-COV2 and Sotrovimab were shown to decrease incidence of death and shortened length of hospital stay in COVID-19 patients [29]. On another note, administration of natural products such as honeysuckle and licorice according to alternative traditional Chinese medicine has shown positive clinical efficacy on SARS-CoV-2 treatment [3]. As such, this opens up a window to consider potential of developing anti-inflammatory therapeutics from natural marine sources such as microalgae.

\section{Microalgae metabolites as potential anti-inflammatory agents to reduce overwhelming inflammation}

Microalgae represent a huge and diverse source of chemically functional compounds with potential pharmaceutical properties that can be drawn from both its primary and secondary metabolism. Immunopathological damage brought upon by a reactive cytokine storm, as often seen in SARS-CoV-2 patients, is a result of hyperactive inflammatory responses resulting in cytokine release syndrome (CRS). Research involving metabolites from microalgae in several implicated immune-related pathways are still relatively few. However, there are several interesting studies that have been carried out that map the auxiliary effects of these metabolites on the immune response pathways using both in vivo and in vitro methods. Available pathophysiology evidence points to a leukocyte-dominated CRS which makes therapeutic adjuncts aimed at blocking IL-6, IL-1 $\beta$ 


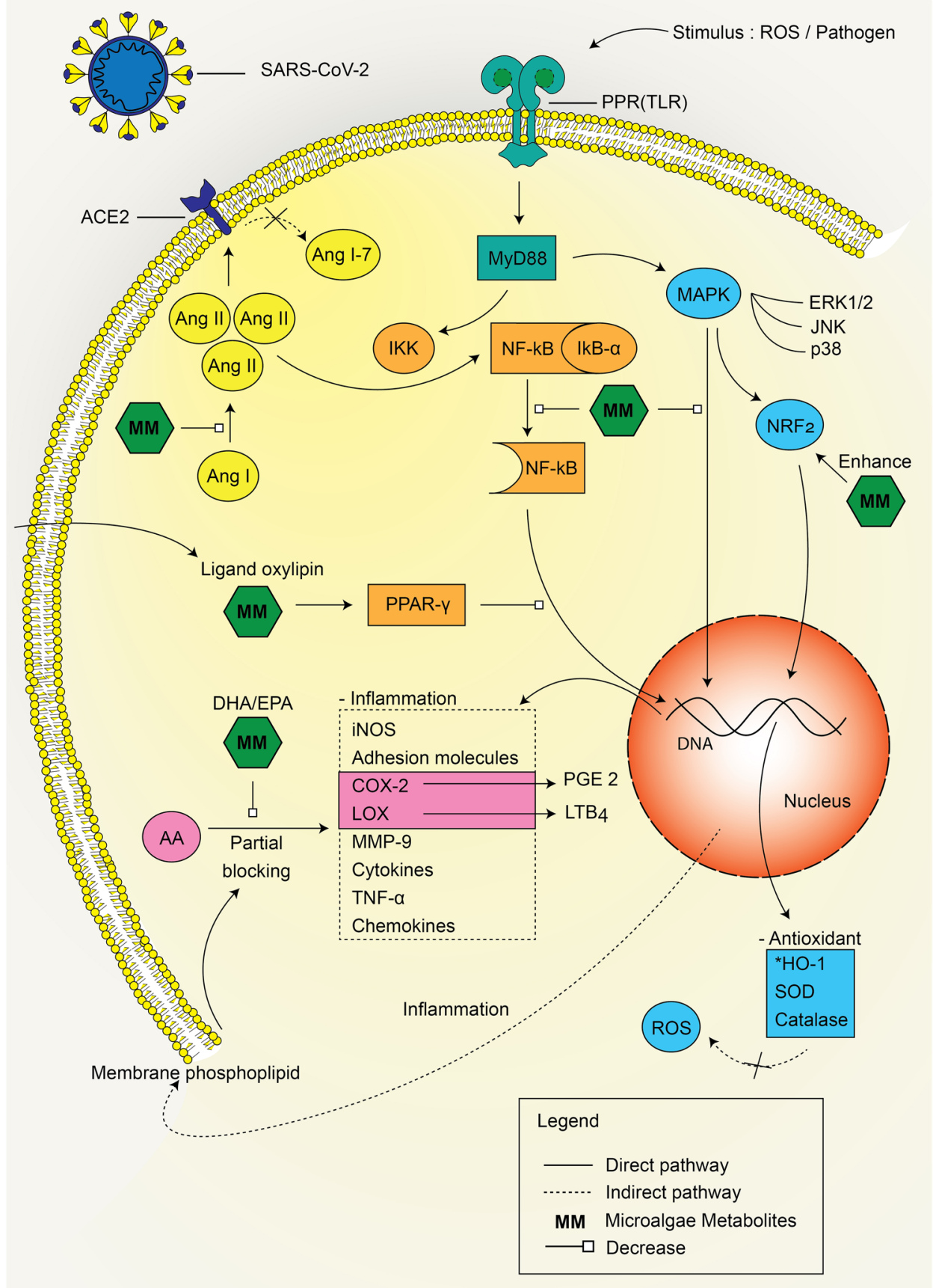

and TNF- $\alpha$ production a viable study potential $[11,14]$. Microalgal metabolites have also been applied in a limited number of clinical trials thus showing that there is value in further developing potential therapeutic candidates based on bioactive microalgal metabolites. Here, some known implicated pathways of the COVID-19 pathology are discussed and juxtaposed along with available research done on several microalgal metabolites.

\section{Renin-angiotensin system (RAS)}

In a study conducted by Chen et al. [25], a novel peptide (amino acid sequence: Phe-Glu-Ile-His-Cys-Cys; molecular weight $750.28 \mathrm{Da}$ ) recovered from Isochrysis zhanjiangenesis was shown to possess the ability to block angiotensinI-converting enzyme (ACE) via a mixed non-competitive mode [25]. The RAS signalling system maintains homeostasis of the vascular functions and is primarily involved in regulation of blood pressure, vascular tone and blood 
४Fig. 3 Known molecular pathways involving anti-inflammatory properties of microalgae metabolites in reducing intensity of inflammatory responses which when left unchecked leads to cytokine storm as observed in COVID-19 patients. Molecular pathway responses of some known metabolites from microalgae involved in anti-inflammatory and antioxidant pathways are mapped. Stimuli received by pattern recognition receptors (PRRs) such as Toll-like receptors (TLR) start off a cascade of pro-inflammatory responses, most probably affecting downstream myeloid differentiation primary response 88 (MyD88). The MM (in green colour) indicates microalgae metabolites that may act as inhibitors or enhancers. The metabolites, mostly peptides, can act on Ang-I (yellow colour) conversion by ACE to reduce pro-inflammatory Ang-II accumulation. Aberrated accumulation of Ang-II can further incite pro-inflammatory signalling pathways such as nuclear factor kappa B pathway (NF- $\mathrm{BB}$; orange colour) and mitogen-activated protein kinase pathway (MAPK; blue colour. The MM majorly act on the pro-inflammatory NF- $\mathrm{kB}$ and MAPK pathways by inhibiting translocation of NF- $\mathrm{\kappa B} / \mathrm{MAPK}$ into the cell's nucleus or preventing dephosphorylation of the kinases from both pathway thus reducing synthesis of pro-inflammatory mediators responsible for inflammation. Certain MM with antioxidant activities particularly work by enhancing nuclear factor erythroid 2-related factor 2 (NRF2) and increase production of antioxidant-related gene expression to reduce reactive oxidative speices (ROS). The arachidonic acid pathway (AA; pink colour) can incidentally be activated by increased inflammatory responses. AA released from cell membrane can be used to produce pro-inflammatory eicosanoids via COX-2 and LOX pathways. MM from the polyunsaturated fatty acid types have been observed to partially block synthesis of pro-inflammatory AA eicosanoids. Lipid derivative of MMs may also play a role as lipid regulators and have been observed to competitively block translocation of NF- $\mathrm{KB}$ into cell nucleus by activating nuclear receptor PPAR- $\gamma$ as a mode to reduce inflammatory responses. MM, microalgae metabolites; IKK, IкB Kinase; MMP-9, matrix metallopeptidase 9; PPAR- $\gamma$, peroxisome proliferator-activated receptor gamma

volume control [26]. Central to this system is the ectoenzyme ACE which is abundantly expressed in the lungs. The ACE dipeptide carboxypeptidase is responsible for converting angiontensin (Ang)-I into the active form of Ang-II (responsible for eliciting vasoconstricting properties) while the ACE2 subtype converts Ang-II into Ang 1-7 (vasodilation promoter) (Fig. 3). Under SARS-CoV-2 infection, the virus compromises ACE2 which leads to higher levels of circulating Ang-II in the blood [2]. The resultant endothelial dysfunction and ARDS is a direct result of the infection and aberrant RAS signalling which contributes to amplified IL-6 production [2]. Due to the ability of SARS-CoV-2 to use ACE2 as sites of cellular entry, there have been calls to repurpose ACE inhibitor drugs to mediate cytokine storms in COVID-19 patients [2,26] and sits on the same page as the purified peptide by Chen et al. [25]. Pro-inflammatory responses elicited by Ang-II include recruitment of inflammatory leukocytes and adhesion molecules that have been shown to increase expression of cyclooxygenase-2 (COX2), nuclear factor kappa B (NF-кB) and mitogen-activated protein kinase (MAPK) pathways [25] (Fig. 3). Treatment application with the peptide on Ang-II-stimulated human umbilical vein cells managed to reduce levels of adhesion molecules (I-CAM and MCP-1), reduced dephosphorylation of IкB $\alpha$ and increased nuclear factor erythroid 2-related factor 2 (NRF2) and heme oxygenase-1 (HO-1) expression. Application of the peptide also reduced oxidative stress as observed by the reduced Jun $\mathrm{N}$-terminal kinases (JNK) signalling of MAPK pathways, showing that the peptide is capable of conferring antioxidant as well as anti-inflammatory properties. Additionally, abnormal Ang-II accumulation and IL-6 stimulation can further hyper-activate nuclear factor kappa B (NF- $\mathrm{KB}$ ) activity via Janus kinase (JAK)/signal transducer and activator of transcription (STAT-3) signalling [2]. Separately, astaxanthin can positively affect inhibition on the STAT-3 pathway by restraining phosphorylation of STAT-3 and its subsequent translocation into cell nucleus [27].

\section{NF-KB and MAPK pathways}

In COVID-19 patients, the NF- $\mathrm{KB}$ pathway plays a pivotal role together with IL-6 stimulated JAK/STAT-3 pathway in the induction of CRS most commonly seen in COVID-19 casualties [2]. The NF- $\mathrm{kB}$ signalling pathway comprises a group of highly conserved family of transcription factors governing many evolutionarily important cellular behaviours pertaining to cell immunity and inflammatory responses [28]. Several microalgae extracts have been proven to exhibit anti-inflammatory properties by acting on the NF- $\mathrm{kB}$ pathway. Usage of microalgae metabolites such as carotenoids, peptides and whole cell extracts have reported effective down-regulation on NF- $\mathrm{\kappa B}$ related pro-inflammatory cytokines (IL-6, TNF- $\alpha$, IL-1 $\beta$ ). Available data confirm that coronavirus infections proceed via pattern-recognition receptors (PRR) such as toll-like receptors (TLR) that detect foreign antigen, aka pathogen- associated molecular patterns (PAMPs), which in turn activates myeloid differentiation factor 88 (MyD88) and the subsequent activation of multisubunit IкB kinase (IKK) (Fig. 3) [2].

Activated IKK then catalyses the phosphorylation of IкB and releases NF- $\kappa B$ (Fig. 3). Free NF- $\kappa B$ is then able to translocate into cell nucleus to activate NF- $\kappa \mathrm{B}$ target genes that generally expresses for pro-inflammatory cytokines (IL-1, IL-6, IL-8, TNF- $\alpha$ ), chemokines and adhesion molecules (ICAM-1, VCAM-1, MMPs) [28]. Molecular studies have indicated that metabolites such as peptides [29] and violaxanthin [30] from Chlorella sp. as well as crude carotenoid extracts [31] were able to reduce translocation of NF- $\mathrm{kB}$ p65/p50 dimers into the nucleus hence ameliorating cytokine production in treated samples. Additionally, ligand/agonist binding to nuclear receptors such as peroxisome proliferator-activated receptor- $\gamma$ (PPAR- $\gamma$ ) has been shown to intercept translocation of NF- $\mathrm{KB}$ into the nucleus (Fig. 3). Ávila-Román et al. [32] demonstrated that a group 
of oxylipins recovered from Chlamydomonas debaryana and Nannochloropsis gaditana were able to act as ligands on PPAR- $\gamma$ to promote subcellular localization of PPAR- $\gamma$ into the nucleus thus reducing NF- $\kappa \mathrm{B}$ dependent inflammatory generation of cytokines [32].

Furthermore, pro-inflammatory stimuli and cellular stress can activate mitogen-activated protein kinase (MAPK) cascade pathways [33]. Consecutive phosphorylations of MAPK signalling elicits constructed inflammation or immune response and cell stress signalling via extracellular-signal-regulated kinase (ERK), p38 and JNK pathways. (Fig. 3). Cytokines have been attributed with activation of MAPK p38 pathway cascades of inflammation as previously observed in SARS-CoV infection and has therefore been suggested as a therapeutic target point for COVID-19 treatment [34]. Microalgae metabolites are therefore potential therapeutics although the anti-inflammatory action of the metabolites is almost always not simultaneously on all three groups of the MAPK pathways. For instance, astaxanthin and docosahexenoic acid (DHA) have been reported to execute anti-inflammatory properties via a p38 dependent pathway in rat model [35] but raw extracts from Phaeodactylum tricornutum target both extracellular signal-regulated kinase (ERK) and p38 in RAW 264.7 macrophage cells [36] while a microalgae peptide from Pavlova lutheri ameliorates via the JNK and p38 MAPK pathway in fibrosarcoma cells [37].

\section{Arachidonic acid pathways}

The arachidonic acid (AA) pathway produces eicosanoids that are involved in the cyclooxygenase (COX) and lipooxygenase (LO) pathways. The AA eicosanoids are also affiliated with/as regulators of NF- $\mathrm{kB}$ pathways involving inflammatory responses [38, 39]. Stimuli on TLRs can stimulate degradation of cell phospholipid membranes by phospholipase-2 ( $\left.\mathrm{PLA}_{2}\right)$ and promote mobilization of membranebound AA [40]. Free AA is then used as precursor in COX-2 and 5-LO pathways that govern inflammation responses via the pro-inflammatory prostaglandin (PGE2) and leukotriene LTB4 production respectively (Fig. 3). Due to difficulty in targeting $\mathrm{PLA}_{2}$ enzymes [40], COX-2, a key enzyme in mediating pro-inflammatory $\mathrm{PGE}_{2}$ has been a preferred target to counter AA products [40]. Metabolites from microalgae with COX-2 inhibiting ability include oxylipins [32], peptides [25], sterols [41], carotenoids [31] and lipids [42] from several groups of microalgae. Due to the fact that PGE2 and leukotriene B4 (LTB4) promotes "leaky" vascular endothelium, the AA pathway has been suggested to be a possible therapeutic target in SARS-CoV-2-induced inflammation by reducing inflammation caused by the endothelium compromise thus reducing migration of leukocytes to site of infection [43].

\section{Human clinical trials involving microalgae metabolites}

To the best of our knowledge, there are currently two known clinical trials that utilize microalgae metabolites on patients with: (i) rheumatoid arthritis [44] and (ii) non-alcoholic fatty liver disease [45]; two conditions that have known inflammation pathologies. This is strong evidence that microalgae metabolites are safe, effective and can be developed into potential therapeutics for human consumption.

Rheumatoid arthritis patients were supplemented with an omega-3 supplement consisting of DHA and EPA from Shizochytrium sp. which targeted AA pathways by competing with AA (an omega-6 PUFA) during eicosanoid production (Fig. 3). The DHA/EPA supplement reduced number of swollen joints while blood parameters showed that the supplement reduced AA:DHA/EPA ratio (Fig. 3) thus reducing blood serum levels of pro-inflammatory AA-derived lipid mediators and ameliorating inflammation conditions [44].

Separately in another study, Chlorella vulgaris whole tablets were supplied to patients with non-alcoholic fatty liver disease. Consumption of the $C$. variabilis whole tablets showed anti-inflammatory properties by effective reduction in TNF- $\alpha$ and C-reactive protein concentrations in blood serum of patients [45]. C-reactive protein has been attributed to poor prognosis for progressive lung destruction in COVID-19 patients, with casualties reporting very high blood serum C-reactive proteins [15].

\section{Natural therapeutic agents against inflammation and cytokine storm}

The major bioactivities of microalgae compounds can be categorized into lipids, phycobilliproteins, chlorophylls, carotenoids, peptides and polyphenols [56]. Among these compounds, lipids and carotenoids are most abundant in microalgae. In microalgae, these compounds are synergistically coordinated during growth and development of microalgae. For example, lipid is a useful component for membrane formation during growth and act as defence mediators during unfavourable conditions while chlorophyll and carotenoids support autotrophic mechanisms of microalgae [56]. As lipid compounds constitute a major component of a microalgae's biomass [56], it is not surprising that several studies on crude extracts have shown that inhibitory effect on proinflammatory cytokines (TNF- $\alpha$, IL-6, IL- $1 \beta$ ) and proinflammatory mediators (prostaglandin (PGE2), nitric oxide (NO), COX-2) were stronger in the non-aqueous fractions. 


\section{Lipids and carotenoids in microalgae biomass}

Ratio of lipids and carotenoids vary between species of microalgae. Some species possessed higher amount of carotenoids than others and same goes to lipids. There are numerous research outputs available from the literature that portray the general idea of carotenoid and lipids in microalgae species. For example, microalga Vischeria stellate was capable to produce a total of $54.5 \mathrm{mg} \mathrm{g}^{-1} \mathrm{DW}$ carotenoid [47] while Neochloris oleoabundans produces only $38.0 \mathrm{mg} \mathrm{g}^{-1} \mathrm{DW}$ of carotenoid [48]. V. stellate is a novel unicellular microalgae which has been genome sequenced while $N$. oleoabundans is a common feedstock for aquaculture industry [47, 48]. Whereas Messastrum gracile which produces $58.0 \%$ DW of total lipid content is regarded as one of the top lipid producer strain [49]. This species is a well-known microalgae that have been intensively studied especially for biodiesel development $[50,51]$.

Carotenoid is an organic pigment that contains unsaturated hydrocarbon substances that play important roles in light harvesting processes and as accessory molecules in photosynthesis [52]. Another important light-harvesting pigment is the xanthophyll group which are able to neutralize over excitation of triplet chlorophylls in order to reduce risk of oxidative stress [53]. Lipids on the other hand can consist on average about 30-40\% of dry weight as reported in Messastrum gracile and Dunaliella tertiolecta [53]. The roles of lipid in microalgae are well discussed in many previous literature. It plays versatile roles in microalgae growth such as monomers for membrane component during growth and proliferation while acting as valuable storage molecules during stress condition [53]. Lipids can be divided into three classes based on its saturation structure: (1) saturated fatty acids (SFA); (2) monounsaturated fatty acids (MUFA); (3) polyunsaturated fatty acids (PUFA). Lipids from microalgae have commercial potentials as third generation biofuels and as health supplements for human consumption, particularly decosahexaenoic acid (DHA) and eicosapentaenoic acid (EPA) [54].

\section{Microalgae rich in anti-inflammatory, antioxidants and immune-modulating compounds}

The promising aspects of microalgae metabolites for purported therapeutic amelioration of aforementioned cytokine/chemokine-triggered inflammation has been studied in the pathology of irritable bowel disease (IBD) [55], rheumatoid arthritis [44], diabetes [56] and artherosclerosis [57]. Most of these anti-inflammatory compounds can be found in the crude and fractionated aqueous, nonpolar (methanol, ethanol, hexane, chloroform) extracts as well as excreted extra-cellularly. Experimental accounts from both in vivo and in vitro studies of these metabolites have reported a range of suppressive function towards proinflammatory cells and signalling biomarkers of which both are important therapeutic target points in the development of anti-inflammatory agents. Interestingly, microalgal lipids were shown to possess good bioavailability and moderate antioxidant activity after stimulated gastrointestinal digestion, thus are viable and have potential to be developed as therapeutic agents for human consumption [58].

\section{Anti-inflammatory compounds}

\section{(i) Peptides and polysaccharides}

In microalgae, amino acids serve many functions including as signalling molecules and catalytic enzymes. Bioactive peptides (BP) are low molecular weight $(<3 \mathrm{kDa})$ short chain amino acids that possess specific 3D configurations which allow them to interact with other biological macroand micro-molecules [59]. Currently, there is growing research interest for microalgal BPs due to their potential anti-oxidant and anti-hypertensive abilities especially in blocking the hypertension-related angiotensin I-converting enzyme (ACE) [60]. The versatility of BPs extends to antiinflammatory effects wherein for instance, Suttisuwan et al. [61] identified 5 peptide sequences from the freshwater microalga Synechococcus sp. that were effective against LPS-stimulated iNOS and NO production, as well as reducing gene expression for COX-2, IL-6 and TNF- $\alpha$ [61]. In a separate study, Ko et al. [74] retrieved a 796.4 Da peptide with seven amino acids using an in vitro gastrointestinal digest mix of pepsin, trypsin and $\alpha$-chymotrypsin carried out on whole Pavolva lutheri cells. The extracted BP displayed high inhibition towards gene expression and protein levels of matrix metalloproteinase-9 (MMP-9) in TPA-stimulated human fibrosarcoma cells. MMP-9 is a common respiratory tract inflammatory marker present in idiopathic pulmonary fibrosis which causes scarring injury to lung tissue [62]. COVID-19 related pneumonia with ARDS also presents with enhanced fibrosis and extracellular matrix remodelling with high neutrophil counts [63]. The onset of respiratory failure linked to increased MMP-9 levels in serum of COVID-19 patients was recently established by Ueland et al. [64]. The authors found that a strong association existed between respiratory failure (lung function measured in $\mathrm{PaO}_{2} / \mathrm{FiO}_{2}$ ratio) and MMP-9 with negative covariance to 
classic inflammatory COVID-19 serum markers C-reactive protein, ferritin and eGFR. The authors thus suggest that MMP-9 could be used as a prognosis for underlying respiratory failure in COVID-19 patients [64]. Ultimately, this makes BPs like the ones from P. lutheri with MMP-9 regulating capabilities a possible candidate for development of adjuvant therapeutics in the treatment of COVID-19 acute lung destruction. Therapeutic efficacy of BPs has also been observed in an IBD-induced mouse model supplemented orally with Schizochytrium sp. protein meal hydrolysate. Gene expression levels of T-cell linked IL-17 and proinflammatory TNF- $\alpha$, IL- 6 and IL- $1 \beta$ cytokines in test subjects were significantly attenuated [65]. Bioactivity in the meal hydrolysate has been linked to several low molecular weight peptides in its protein profile [65]. Repair in mucosal organisation in the afflicted mouse models was also reported thus proving that BPs are capable of initiating some level of inflammation resolution.

Sulfated polysaccharides have gained a lot of attention from studies carried out on Spirulina for their anti-viral as well as anti-inflammatory properties [66]. In microalgae, Guzmán et al. [62] demonstrated the anti-inflammatory properties of sulphated polysaccharides from green algae Chlorella stigmatophora and diatom Phaedactylum tricornatum. Although the polysaccharides were low in sulphated portions ( $7-11 \%$ per lyophilized weight), inflammation was attenuated in carrageenan-induced paw edema models and had even performed better than the anti-inflammatory drug indomethacin [62]. Polysaccahrides from different classes of algae have shown potential to act as antogonists on toll-like receptors (TLR) which once activated, elicits a strong inflammatory response on mononuclear macrophages [67]. The TLR receptors can be activated in influenza infections via the release of damage-associated molecular patterns molecules and has been recognized as the cause of acute lung injury in influenza-infected mouse models via the activated release of alveolar macrophage cytokines [68]. TLRs specifically invoke inflammatory responses via the

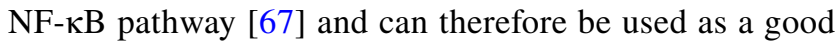
point of reference to screen for prospective bioactive microalgal polysaccharides. The cytokine release also increases adhesion molecule activity in endothelial lining of the respiratory tract. Both vascular cell adhesion 1 (VCAM-1) and intercellular adhesion molecule 1 (ICAM-1) play roles in aggregation and facilitation of leukocyte migration into site of infection which leads to endothelial dysfunction [57]. Serum concentration of adhesion molecules VCAM- 1 and ICAM-1 increased with pathology severity of COVID-19 patients while reduction in ICAM- 1 and VCAM- 1 correlated with higher recovery rates [69]. Adhesion molecule attenuation can be obtained via microalgae polysaccharides. LevyOntman et al. [57] illustrated the reducing effect of Porphyridium sp. derived polysaccharides on TNF- $\alpha$ stimulated
ICAM-1 and VCAM-1 in human coronary artery endothelial cells. The polysaccharide had also possessed the ability to mediate NO production, an important vasodilator in endothelial systems [57].

\section{(ii) Lipids}

The phospholipid bilayer of microalgae can consists of many structural lipids that play important roles in the maintenance of normal cell physiology. Membrane glycolipids in microalgae are mainly the glyceroglycolipids MGDG and DGDG. In LPS-stimulated models of RAW 264.7 and THP-1 macrophages, the glyceroglycolipids MGDG and DGDG extracted from Tetraselmis chui [70] and Nannochloropsis granulata [70] successfully reduced NO activity while Isochrysis galbana reportedly lowered TNF- $\alpha$ production [71]. In a recent discovery, two methanol fractions from the marine diatom Cylindrotheca closterium exhibited TNF- $\alpha$ suppressive activity in lipopolysaccharide (LPS)-stimulated human monocyte THP-1 cell model. Further dereplication of the fractions attributed the anti-inflammatory activity to the presence of a choline-containing phospholipid known as lysophosphatidylcholine and a chlorophyllrelated hydroxypheophorbide $a$ [72]. Another interesting class of lipids are the phystosterols. Phytosterols extracted from methanol and hexane-soluble fractions have also been proven to exhibit anti-inflammatory and tentative immunomodulatory bioactivity in a dose-dependent manner [41]. Several microalgal phytosterols were first identified from Chlorella vulgaris and were successful in reducing 12-O-tetradecanoylphorbol-13-acetate (TPA)-induced edema in mouse ears besides showing anti-proliferative effect on mouse skin tumour [73]. In LPS-induced inflammation in sheep peripheral blood mononuclear cell models, phytosterol extracts from the diatom Dunaliella tertiolecta were successful in reducing proinflammatory cytokines TNF- $\alpha$, IL-6 and IL-1 $\beta$ [74]. The suppression of inflammatory reactions in both studies have been linked to the larger proportions of ergosterol, 7-dehydroporiferasterol and ergosterol peroxide content in the extracts $[73,74]$.

\section{(iii) Pigments}

Light-harvesting cholorophyll and the accessory carotenoid pigments have been found to positively affect anti-inflammatory cellular responses and mechanisms via their antioxidant nature. Most recently astaxanthin, the most popular health carotenoid, has been suggested for therapeutic use in the modulation of immune responses and to reduce exacerbated cytokine production in SARS-CoV-2 patients [5]. Extensive research using astaxanthin in pre-clinical models [75] as well as in clinical trials [76] have presented strong evidences touting its clinical benefits particularly for astaxanthin's 
antioxidant led anti-inflammatory capabilities. Other popular carotenoids such as $\beta$-carotenoid, violaxanthin, zeaxanthin, and fucoxanthin have also gained attention for their reported anti-inflammatory activities. For instance, violaxanthin from Chlorella ellipsoidea [30] and fucoxanthin derived from Conticriba weissflogi [77] were found to exhibit antiinflammatory effects on LPS-induced IL-6, IL- $1 \beta$, TNF- $\alpha$ and inducible nitric oxide (iNOS) in both in vivo and in vitro mouse models. In an interesting experiment to test inflammation elicited via pseudorabies virus (PRV) infection on RAW264.7 macrophage cells, proinflammatory cytokines (IL-1 $\beta$, IL-6, TNF- $\alpha$, MCP-1) and mediators (iNOS, COX-2) were brought under control by $\beta$-carotenoid and $\alpha$-carotenoid extracted from Dunaliella salina [31]. Indeed, this represents substantiate evidence on the ability to superimpose knowledge from anti-inflammatory activities using known inflammatory stimulants onto virus-triggered inflammatory mechanisms. On a more recent note, a form of chlorophyllbreakdown product, hydroxypheophorbide $a$ was isolated from diatom $C$. closterium and found to be effective in reducing TNF- $\alpha$ levels [72]. Pheophorbide $a$ is commonly sourced from green-leafy plants and is usually reported to possess good anti-cancer activities [78] thus this marks a first for reported anti-inflammatory properties from a microalgae-sourced pheophorbide [72].

\section{Antioxidant feature}

Another feature of the cytokine storm is the unavoidable dysregulated production of reactive oxygen species (ROS) which is caused by populous recruitment of immune cells such as monocytes and macrophages at point of infection. Antioxidant agents scavenge for free radicals, restore dysfunctioned mechanisms and regulate oxidative-stress mediated pathways [79]. The antioxidative capabilities of several metabolites, specifically the carotenoid group of pigments as well as some tocopherols, flavonoids and phenolic compounds are well documented. For instance, crude methanol/water extract from Tetraselmis suecica that contained luthein, violaxanthin, neoxantin and chlorophyll b was effective in regulating gene expression of several hydrogen peroxide $\left(\mathrm{H}_{2} \mathrm{O}_{2}\right)$-induced oxidative stress besides reducing prostaglandin E2 (PGE2) levels in cells damaged by $\mathrm{H}_{2} \mathrm{O}_{2}$ [80]. Exacerbated production of ROS and $\mathrm{H}_{2} \mathrm{O}_{2}$ has been implicated in the pathological mechanisms of many respiratory viral infections (although not directly confirmed in COVID-19), leading to dysregulation of mitochondrial membranes which eventually induces acute lung injury [81]. In order to negate these negative effects of oxidative stress, clinical use of apocynin, a superoxide inhibitor is used to block off NADPH oxidase (a free radical receptor) and NF- $\kappa B$ pathways [82]. In this regard, Li et al. [83] showed that fucoxanthin treatment helped restore redox concentrations by promoting biogenesis of mitochondrial-related proteins and also initiated mitophagy on disrupted mitochondria in macrophages hence improving mitochondria dysfunction. Another carotenoid astaxanthin, has also demonstrated antioxidative effects via amelioration of mitochondrial membrane dysfunction as well as decreasing NF- $\mathrm{\kappa B}$ expression in human gastric epithelial cells [84].

Interestingly, there is growing recognition for the antioxidant and anti-inflammatory capabilities of microalgaesourced polysaccharides (PS) and extracellular polymeric substances EPS. In nature, microalgae may rely on the biochemical complexity of PS and EPS to serve both structural and protective purposes as well as for adhesion. A thorough review on the chemical diversity of microalgal PS and EPS and their resulting biological activities has been done by Prybylski et al. [85]. However pathway mechanisms of these microalgae PS (sulphated or non-sulfated) and EPS remain unknown and warrants further research as there have been many positive reports on the ROS scavenging capabilities of EPS from Chlorococcum sp. and Scenedesmus sp. - DPPH radical and hydroxyl radicals [86], Chlamydomonas reinhardtii [87] and Rhodella reticulata - superoxide radical ion [88]; as well as polysaccharides from Isochrysis galbana - superoxide radical ion and hydroxyl radical, $\mathrm{H}_{2} \mathrm{O}_{2}$ [89], Nannochloropsis oculata - DPPH radical [90] and sulphated polysaccharide from Navicula sp. - DPPH radical, ABTS radical [91]. The NRF2 pathway (Fig. 3) majorly regulates oxidative stress-related proteins and although substantial evidence involving COVID-19 cases are still pending, the pathway has been implicated previously in several viral infections in humans. Hooper [92] however did note that low heme oxygenase-1 (HO-1) reading contributed to mortality rates of elderly COVID-19 patients and suggested that therapeutics that counter reduction of HO-1 may improve patient outlook. Studies show that polysaccharides from seaweed and microalgae peptides antioxidant exert their antioxidative prowess via activation of NRF2 pathways through the transcription of cytoprotective genes such as HO-1 [93]. Taking a cue from previous research, there is possibility that microalgal PS and EPS may affect these pathways too.

Polyphenols on the other hand are lesser studied in microalgae but current available data from new microalgae strains prove their ROS scavenging abilities [94]. While Cardoso et al. [94] attributed antioxidant activity to a mixture of $\omega-3$ PUFAs and phenolic compounds [94], Haoujar et al. [95] and Jerez-Martel et al. [96] described the strong ROS scavenging capability of the microalgae extracts to phenolic compounds such as gallic acid and protocatechuic acid. Polyphenols are acknowledged to directly modulate mitochondria biogenesis and redox states [97] and are therefore worth further perusing. Essentially, resultant antioxidant activity may comprise the synergistic involvement of 
a multitude of non-polar metabolites as observed in a study comparing $\beta$-carotene from Dunaliella salina extracts and synthesised $\beta$-carotene and can be considered as a therapeutic development strategy.

\section{Immunomodulating activity}

Interestingly, microalgae extracts have also been reported to possess immunomodulatory properties. Microalgal EPS sourced from Thraustochytriidae sp. could increase B cell proliferation independently of $\mathrm{T}$ cells therefore showcasing its abilities in potentiation of humoral responses [98]. Although antibody titre and B cell type was not justified in the study, this depicts possible antibody promoting effects or a possible modulation on cell-mediated immune responses by the EPS. There have been several reports of immunestimulatory and anti-inflammatory effects of EPS but this is the first study to our knowledge that measured lymphocyte response towards a microalgal metabolite. In a separate review, B cells were found to influence efficiency of viralload clearance from host, improve immune response against recurring mutated influenza viral strains as well as deflecting onset of severe influenza virus pathology in mice models [99]. The role of B cells in antibody-resolved COVID-19 infections suffers from lack of data but is nonetheless an equally important equation of the functional immune system as cytokine markers from both innate and adaptive cell types were reported in severe cases. Back on the subject of EPS administration, the metabolite also caused a reduction in IL-6 and IFN- $\gamma$ levels following LPS stimulation [98] thus showing that the EPS component has potential in promoting possible down-regulation of cytokine storms.

Polysaccharides [62] and sulphated polysaccharides [100] from several microalgae have been noted to be able to increase phagocytosis rates in macrophages. Although phagocytosis is central for eliminating invading pathogens and the onset of inevitable inflammation, the process is equally important for the resolution of inflammation and tissue homeostasis restoration. Although the present studies do not study the phagocytosis activity under defined conditions of either resolution or pro-inflammatory states, stimulation of phagocytosis is still a positive sign for future applications of drug developments.

\section{Conclusion and future outlook}

Going forward, there is substantial evidence for potentiating further development of microalgal metabolites for use as therapeutic agents in relieving CRS as observed in COVID19 patients. Unfortunately, microalgae metabolites are rarely tested on viral-induced inflammatory responses. However, in regards to available in vitro/in vivo studies as well as clinical trials, ability of microalgal metabolites in mitigating inflammatory responses relay a positive message suggesting that its application is not only restricted to just inflammation caused in viral respiratory infections but may also find credible use in other inflammation progressive diseases. The use of available generic drugs together with effective natural therapeutics from microalgae could be highly useful strategy should we face future coronavirus pandemics. Other than anti-inflammatory responses, some microalgae metabolites also seem to enhance defence mechanisms such as responses seen in the different groups of activated MAPK pathways as well as in eliciting immune-modulating responses in lymphocytes.

Acknowledgements The authors gratefully acknowledge support from the Japan Science and Technology Agency (JST)/Japan International Cooperation Agency (JICA), Science and Technology Research Partnership for Sustainable Development (SATREPS) through the project for Continuous Operation System for Microalgae Production Optimized for Sustainable Tropical Aquaculture (COSMOS), and the SATREPSCOSMOS Matching Fund from the Ministry of Higher Education Malaysia (MOHE) [Grant No. VOT 53222].

Author contributions All authors contributed to the writing, reviewing and editing of the manuscript. CLWA and KYT contributed equally and substantially to researching content and discussion of the content for the article.

\section{Declarations}

Conflict of interest The authors declare no competing interests.

\section{References}

1. World Health Organization (WHO) (2021) Coronavirus (COVID19) Dashboard. World Health Organization. https://covid19.who. int/

2. Hirano T, Murakami M (2020) COVID-19: a new virus, but a familiar receptor and cytokine release syndrome. Immunity 52:731-733. https://doi.org/10.1016/j.immuni.2020.04.003

3. Luo H, Gao Y, Zou J, Zhang S, Chen H, Liu Q, Tan D, Han Y, Zhao Y, Wang S (2020) Reflections on treatment of COVID-19 with traditional Chinese medicine. Chin Med 15:1-14. https:// doi.org/10.1186/s13020-020-00375-1.eCollection

4. Elagoz AM, Ambrosino L, Lauritano C (2020) De novo transcriptome of the diatom Cylindrotheca closterium identifies genes involved in the metabolism of anti-inflammatory compounds. Sci Rep 10:1-9. https://doi.org/10.1038/s41598-020-61007-0

5. Talukdar J, Dasgupta S, Nagle V, Bhadra B (2020) COVID-19: potential of microalgae derived natural astaxanthin as adjunctive supplement in alleviating cytokine storm. SSRN Electron J. https://doi.org/10.2139/ssrn.3579738

6. Shereen MA, Khan S, Kazmi A, Bashir N, Siddique R (2020) COVID-19 infection: origin, transmission, and characteristics of human coronaviruses. J Adv Res 24:91-98. https://doi.org/10. 1016/j.jare.2020.03.005

7. Du Z, Javan E, Nugent C, Cowling BJ, Meyers LA (2020) Using the COVID-19 to influenza ratio to estimate early 
pandemic spread in Wuhan, China and Seattle. US E Clin Med. https://doi.org/10.1016/j.eclinm.2020.100479

8. Fan E, Beitler JR, Brochard L, Calfee CS, Ferguson ND, Slutsky AS, Brodie D (2020) COVID-19-associated acute respiratory distress syndrome: is a different approach to management warranted? Lancet Respir Med 8:816-821. https://doi.org/10. 1016/S2213-2600(20)30304-0

9. V'kovski P, Kratzel A, Steiner S, Stalder H, Thiel V (2021) Coronavirus biology and replication: implications for SARSCoV-2. Nat Rev Microbiol 19:155-170. https://doi.org/10. 1038/s41579-020-00468-6

10. Romano M, Ruggiero A, Squeglia F, Maga G, Berisio R (2020) A structural view of SARS-CoV-2 RNA replication machinery: RNA synthesis, proofreading and final capping. Cells 9:1267. https://doi.org/10.3390/cells9051267

11. Lu L, Zhang H, Zhan M, Jiang J, Yin H, Dauphars DJ, Li SY, Li Y, He YW (2020) Preventing mortality in COVID-19 patients: which cytokine to target in a raging storm? Front Cell Dev Biol 8:1-8. https://doi.org/10.3389/fcell.2020.00677.eColl ection

12. Moldoveanu B, Otmishi P, Jani P, Walker J, Sarmiento X, Guardiola J, Saad M, Yu J (2009) Inflammatory mechanisms in the lung. J Inflamm Res 2:1-11. https://doi.org/10.2147/jir.s4385

13. Conti P, Ronconi G, Caraffa A, Gallenga CE, Ross R, Frydas I, Kritas SK (2020) Induction of pro-inflammatory cytokines (IL-1 and IL-6) and lung inflammation by coronavirus-19 (COVID19 or SARS-CoV-2): anti-inflammatory strategies. J Biol Regul Homeost Agents 34:1-5. https://doi.org/10.23812/CONTI-E

14. Zhou F, Yu T, Du R, Fan G, Liu Y, Liu Z, Xiang J, Wang Y, Song B, Gu X, Guan L, Wei Y, Li H, Wu X, Xu J, Tu S, Zhang Y, Chen H, Cao B (2020) Clinical course and risk factors for mortality of adult inpatients with COVID-19 in Wuhan, China: a retrospective cohort study. Lancet 395:1054-1062. https://doi. org/10.1016/S0140-6736(20)30566-3

15. Tang Y, Liu J, Zhang D, Xu Z, Ji J (2020) Wen C (2020) Cytokine storm in COVID-19: the current evidence and treatment strategies. Front Immunol 11:1-13. https://doi.org/10.3389/fimmu. 2020.01708.eCollection

16. Yang L, Xie X, Tu Z, Fu J, Xu D, Zhou Y (2021) The signal pathways and treatment of cytokine storm in COVID-19. Signal Transduct Target Ther 6:1-20. https://doi.org/10.1038/ s41392-021-00679-0

17. Bao J, Li C, Zhang K, Kang H, Chen W, Gu B (2020) Comparative analysis of laboratory indexes of severe and non-severe patients infected with COVID-19. Clin Chim Acta 509:180-194. https://doi.org/10.1016/j.cca.2020.06.009

18. Gordon CJ, Tchesnokov EP, Feng JY, Porter DP, Götte M (2020) The antiviral compound remdesivir potently inhibits RNAdependent RNA polymerase from Middle East respiratory syndrome coronavirus. J Biol Chem 295:4773-4779. https://doi. org/10.1074/jbc.AC120.013056

19. Yin W, Mao C, Luan X, Shen DD, Shen Q, Su H, Wang X, Zhou F, Zhao W, Gao M, Chang S, Xie YC, Tian G, Jiang HW, Tao SC, Shen J, Jiang Y, Jiang H, Xu Y, Zhang S, Zhang Y, Xu HE (2020) Structural basis for inhibition of the RNA-dependent RNA polymerase from SARS-CoV-2 by remdesivir. Science 368:1499-1504. https://doi.org/10.1126/science.abc1560

20. Offerhaus JA, Wilde AAM, Remme CA (2020) Prophylactic (hydroxy)chloroquine in COVID-19: potential relevance for cardiac arrhythmia risk. Hear Rhythm 17:1480-1486. https:// doi.org/10.1016/j.hrthm.2020.07.001

21. WHO (2020) WHO discontinues hydroxychloroquine and lopinavir/ritonavir treatment arms for COVID-19. World Health Organisation, pp. 1-2. https://www.who.int/news/item/04-072020-who-discontinues-hydroxychloroquine-and-lopinavir-riton avir-treatment-arms-for-covid-19
22. Graham G, Scott K (2005) Mechanism of action of paracetamol. Am J Ther 12:46-55. https://doi.org/10.1097/00045391-20050 $1000-00008$

23. Jamerson BD, Haryadi TH (2020) The use of ibuprofen to treat fever in COVID-19: a possible indirect association with worse outcome? Med Hypotheses 144:1-2. https://doi.org/10.1016/j. mehy.2020.109880

24. Kallen KJ (2002) The role of transsignalling via the agonistic soluble IL-6 receptor in human diseases. Biochim Biophys Acta 1592:323-343. https://doi.org/10.1016/s0167-4889(02)00325-7

25. Chen J, Tan L, Li C, Zhou C, Hong P, Sun S, Qian ZJ (2020) Mechanism analysis of a novel angiotensin-I-converting enzyme inhibitory peptide from Isochrysis zhanjiangensis microalgae for suppressing vascular injury in human umbilical vein endothelial cells. J Agric Food Chem 68:4411-4423. https://doi.org/10.1021/ acs.jafc.0c00925

26. Evans PC, EdRainger G, Mason JC, Guzik TJ, Osto E, Stamataki Z, Neil D, Hoefer IE, Fragiadaki M, Waltenberger J, Weber C, Bochaton-Piallat M-L, Bäck M (2020) Endothelial dysfunction in COVID-19: a position paper of the ESC Working Group for Atherosclerosis and Vascular Biology, and the ESC Council of Basic Cardiovascular Science. Cardiovasc Res 230:1-21. https:// doi.org/10.1093/cvr/cvaa230

27. Kowshik J, Baba AB, Giri H, Reddy GD, Dixit M, Nagini S (2014) Astaxanthin inhibits JAK/STAT-3 signaling to abrogate cell proliferation, invasion and angiogenesis in a hamster model of oral cancer. PLoS ONE 9:1-14. https://doi.org/10.1371/journ al.pone. 0109114

28. Liu T, Zhang L, Joo D, Sun SC (2017) NF- $\kappa B$ signaling in inflammation. Signal Transduct Target Ther 2:1-9. https://doi. org/10.1038/sigtrans.2017.23

29. Cherng JY, Liu CC, Shen CR, Lin HH, Shih MF (2010) Beneficial effects of Chlorella-11 peptide on blocking LPS-induced macrophage activation and alleviating thermal injury-induced inflammation in rats. Int J Immunopathol Pharmacol 23:811820. https://doi.org/10.1177/039463201002300316

30. Soontornchaiboon W, Joo SS, Kim SM (2012) Anti-inflammatory effects of violaxanthin isolated from microalga Chlorella ellipsoidea in RAW 264.7 macrophages. Biol Pharm Bull 35:11371144. https://doi.org/10.1248/bpb.b12-00187

31. Lin HW, Chen YC, Liu CW, Yang DJ, Chen SY, Chang TJ, Chang YY (2014) Regulation of virus-induced inflammatory response by Dunaliella salina alga extract in macrophages. Food Chem Toxicol 71:159-165. https://doi.org/10.1016/j.fct.2014.05.026

32. Ávila-Román J, Talero E, de los Reyes C, García-Mauriño S, Motilva V (2018) Microalgae-derived oxylipins decrease inflammatory mediators by regulating the subcellular location of $\mathrm{NF \kappa B}$ and PPAR- $\gamma$. Pharmacol Res 128:220-230. https://doi.org/10. 1016/j.phrs.2017.10.009

33. Soares-Silva M, Diniz FF, Gomes GN, Bahia D (2016) The mitogen-activated protein kinase (MAPK) pathway: role in immune evasion by trypanosomatids. Front Microbiol 7:1-9. https://doi. org/10.3389/fmicb.2016.00183

34. Grimes JM, Grimes KV (2020) p38 MAPK inhibition: a promising therapeutic approach for COVID-19. J Mol Cell Cardiol 144:63-65. https://doi.org/10.1016/j.yjmcc.2020.05.007

35. Mimouni V, Ulmann L, Pasquet V, Mathieu M, Picot L, Bougaran G, Cadoret J-P, Morant-Manceau A, Schoefs B (2012) The potential of microalgae for the production of bioactive molecules of pharmaceutical interest. Curr Pharm Biotechnol 13:2733-2750. https://doi.org/10.2174/138920112804724828

36. Neumann U, Louis S, Gille A, Derwenskus F, Schmid-Staiger U, Briviba K, Bischoff SC (2018) Anti-inflammatory effects of Phaeodactylum tricornutum extracts on human blood mononuclear cells and murine macrophages. J Appl Phycol 30:28372846. https://doi.org/10.1007/s10811-017-1352-7 
37. Ko SC, Heo SY, Choi SW, Qian ZJ, Heo SJ, Kang DH, Kim $\mathrm{N}$, Jung WK (2018) A heptameric peptide isolated from the marine microalga Pavlova lutheri suppresses PMA-induced secretion of matrix metalloproteinase-9 through the inactivation of the JNK, p38, and NF-KB pathways in human fibrosarcoma cells. J Appl Phycol 30:2367-2378. https://doi.org/10.1007/ s10811-018-1443-0

38. Ramakers JD, Mensink RP, Schaart G, Plat J (2007) Arachidonic acid but not eicosapentaenoic acid (EPA) and oleic acid activates NF- $\mathrm{KB}$ and elevates ICAM-1 expression in Caco- 2 cells. Lipids 42:687-698. https://doi.org/10.1007/s11745-007-3071-3

39. Yarla NS, Sukocheva O, Peluso I, Putta S, Bramhachari PV, Yadala R, Tiwari DK, Jagarlamudi S, Scotti L, Scotti MT, Reale M, Kamal MA, Ghulam A, Sharma B, Parvathaneni M, Rao CV, Mannarapu M, Bishayee A (2018) Targeting arachidonic acid pathway-associated NF- $\kappa$ B in pancreatic cancer. Role Transcr Factors Gastrointest Malig. https://doi.org/10.1007/978-981-106728-0 30

40. Astudillo AM, Pérez-Chacón G, Balboa MA, Balsinde J (2009) Arachidonic acid mobilization by stimuli of the innate immune response. Inmunologia 28:182-192. https://doi.org/10.1016/ S0213-9626(09)70041-1

41. Sanjeewa KKA, Fernando IPS, Samarakoon KW, Lakmal HHC, Kim EA, Kwon ON, Dilshara MG, Lee JB, Jeon YJ (2016) Antiinflammatory and anti-cancer activities of sterol rich fraction of cultured marine microalga Nannochloropsis oculata. Algae 31:277-287. https://doi.org/10.4490/algae.2016.31.6.29

42. Bonfanti C, Cardoso C, Afonso C, Matos J, Garcia T, Tanni S, Bandarra NM (2018) Potential of microalga Isochrysis galbana: bioactivity and bioaccessibility. Algal Res 29:242-248. https:// doi.org/10.1016/j.algal.2017.11.035

43. Hoxha M (2020) What about COVID-19 and arachidonic acid pathway? Eur J Clin Pharmacol 25:1-4. https://doi.org/10.1007/ s00228-020-02941-w

44. Dawczynski C, Dittrich M, Neumann T, Goetze K, Welzel A, Oelzner P, Völker S, Schaible AM, Troisi F, Thomas L, Pace S, Koeberle A, Werz O, Schlattmann P, Lorkowski S, Jahreis $\mathrm{G}$ (2018) Docosahexaenoic acid in the treatment of rheumatoid arthritis: a double-blind, placebo-controlled, randomized crossover study with microalgae vs. sunflower oil. Clin Nutr 37:494504. https://doi.org/10.1016/j.clnu.2017.02.021

45. Ebrahimi-Mameghani M, Sadeghi Z, Abbasalizad Farhangi M, Vaghef-Mehrabany E, Aliashrafi S (2017) Glucose homeostasis, insulin resistance and inflammatory biomarkers in patients with non-alcoholic fatty liver disease: beneficial effects of supplementation with microalgae Chlorella vulgaris: a double-blind placebo-controlled randomized clinical trial. Clin Nutr 36:10011006. https://doi.org/10.1016/j.clnu.2016.07.004

46. Singh P, Khadim R, Singh AK, Singh U, Maurya P, Tiwari A, Asthana RK (2019) Biochemical and physiological characterization of a halotolerant Dunaliella salina isolated from hypersaline Sambhar Lake, India. J Phycol 55:60-73. https://doi.org/10.1111/ jpy. 12777

47. Li Z, Sun M, Li Q, Li A, Zhang C (2012) Profiling of carotenoids in six microalgae (Eustigmatophyceae) and assessment of their $\beta$-carotene productions in bubble column photobioreactor. Biotechnol Lett 34:2049-2053. https://doi.org/10.1007/ s10529-012-0996-2

48. Huang L, Gao B, Wang F, Zhao W, Zhang C (2019) The complete chloroplast genome of an edaphic oleaginous microalga Vischeria stellata SAG 33.83 (Eustigmatophyceae). Mitochondrial DNA Part B Resour 4:1041-1043. https://doi.org/10.1080/ 23802359.2019.1580166

49. Wan Afifudeen CL, Loh SH, Aziz A, Takahashi K, Abd Wahid ME, Cha TS (2021) Double-high in palmitic and oleic acids accumulation in a non-model green microalga, Messastrum gracile
SE-MC4 under nitrate -repletion and -starvation cultivations. Sci Rep 11:382. https://doi.org/10.1038/s41598-020-79711-2

50. Teh KY, Wan Afifudeen CL, Aziz A, Wong LL, Loh SH, Cha TS (2019) De novo whole genome sequencing data of two mangrove-isolated microalgae from Terengganu coastal waters. Data Br 27:104680. https://doi.org/10.1016/j.dib.2019.104680

51. Wan Afifudeen CL, Aziz A, Wong LL, Takahashi K, Toda T, Abd Wahid ME, Cha TS (2021) Transcriptome-wide study in the green microalga Messastrum gracile SE-MC4 identifies prominent roles of photosynthetic integral membrane protein genes during exponential growth stage. Phytochemistry 192:112936. https://doi.org/10.1016/j.phytochem.2021.112936

52. Vaquero I, Mogedas B, Ruiz-domínguez MC, Vega JM, Vílchez C (2014) Light-mediated lutein enrichment of an acid environment microalga. Algal Res 6:70-77. https://doi.org/10.1016/j. algal.2014.09.005

53. Zhu S, Feng P, Feng J, Xu J, Wang Z, Xu J, Yuan Z (2018) The roles of starch and lipid in Chlorella sp. during cell recovery from nitrogen starvation. Bioresour Technol 247:58-65. https:// doi.org/10.1016/j.biortech.2017.08.120

54. Koyande AK, Chew KW, Rambabu K, Tao Y, Chu D-T, Show P-L (2019) Microalgae: a potential alternative to health supplementation for humans. Food Sci Hum Wellness 8:16-24. https:// doi.org/10.1016/j.fshw.2019.03.001

55. Yang YP, Tong QY, Zheng SH, Zhou MD, Zeng YM, Zhou TT (2020) Anti-inflammatory effect of fucoxanthin on dextran sulfate sodium-induced colitis in mice. Nat Prod Res 34:1791-1795. https://doi.org/10.1080/14786419.2018.1528593

56. Lauritano C, Andersen JH, Hansen E, Albrigtsen M, Escalera L, Esposito F, Helland K, Hanssen K, Romano G, Ianora A (2016) Bioactivity screening of microalgae for antioxidant, anti-inflammatory, anticancer, anti-diabetes, and antibacterial activities. Front Mar Sci 3:1-2. https://doi.org/10.3389/fmars.2016.00068

57. Levy-Ontman O, Huleihel M, Hamias R, Wolak T, Paran E (2017) An anti-inflammatory effect of red microalga polysaccharides in coronary artery endothelial cells. Atherosclerosis 264:11-18. https://doi.org/10.1016/j.atherosclerosis.2017.07.017

58. Lv J, Yang X, Ma H, Hu X, Wei Y, Zhou W, Li L (2015) The oxidative stability of microalgae oil (Schizochytrium aggregatum) and its antioxidant activity after simulated gastrointestinal digestion: relationship with constituents. Eur J Lipid Sci Technol 117:1928-1939. https://doi.org/10.1002/ejlt.201400588

59. Apone F, Barbulova A, Colucci MG (2019) Plant and microalgae derived peptides are advantageously employed as bioactive compounds in cosmetics. Front Plant Sci 10:1-8. https://doi.org/ 10.3389/fpls.2019.00756

60. Li Y, Lammi C, Boschin G, Arnoldi A, Aiello G (2019) Recent advances in microalgae peptides: cardiovascular health benefits and analysis. J Agric Food Chem 67:11825-11838. https://doi. org/10.1021/acs.jafc.9b03566

61. Suttisuwan R, Phunpruch S, Saisavoey T, Sangtanoo P, Thongchul N, Karnchanatat A (2019) Isolation and characterization of anti-inflammatory peptides derived from trypsin hydrolysis of microalgae protein (Synechococcus sp. VDW). Food Biotechnol 33:303-324. https://doi.org/10.1080/08905436.2019.1673171

62. Guzmán S, Gato A, Lamela M, Freire-Garabal M, Calleja JM (2003) Anti-inflammatory and immunomodulatory activities of polysaccharide from Chlorella stigmatophora and Phaeodactylum tricornutum. Phyther Res 17:665-670. https://doi.org/10. $1002 /$ ptr. 1227

63. George PM, Wells AU, Jenkins RG (2020) Pulmonary fibrosis and COVID-19: the potential role for antifibrotic therapy. Lancet Respir Med 8:807-815. https://doi.org/10.1016/S2213-2600(20) 30225-3

64. Ueland T, Holter JC, Holten AR, Müller KE, Lind A, Bekken GK, Dudman S, Aukrust P, Dyrhol-Riise AM, Heggelund 
L (2020) Distinct and early increase in circulating MMP-9 in COVID-19 patients with respiratory failure: MMP-9 and respiratory failure in COVID-19. J Infect 81:e41-e43. https://doi.org/ 10.1016/j.jinf.2020.06.061

65. Wang X, Wang H, Pierre JF, Wang S, Huang H, Zhang J, Liang S, Zeng Q, Zhang C, Huang M, Ruan C, Lin J, Li H (2018) Marine microalgae bioengineered Schizochytrium sp. meal hydrolysates inhibits acute inflammation. Sci Rep 8:1-11. https://doi.org/10. 1038/s41598-018-28064-y

66. Capelli B, Cysewski GR (2010) Potential health benefits of spirulina microalgae. Nutrafoods 9:19-26. https://doi.org/10.1007/ bf03223332

67. Tominaga A, Okuyama H, Fukuoka S, Taguchi T, Kusumoto Y, Shimizu K, Ono S (2012) Effects of edible algae polysaccharides on allergic, inflammatory, and anti-tumor responses through toll-like receptor 4. Antiinflamm Antiallergy Agents Med Chem 9:238-250. https://doi.org/10.2174/1871523011009030238

68. Thomas G, Frederick E, Hausburg M, Goldberg L, Hoke M, Roshon M, Mains C, Bar-Or D (2020) The novel immunomodulatory biologic LMWF5A for pharmacological attenuation of the "cytokine storm" in COVID-19 patients: a hypothesis. Patient Saf Surg 14:1-11. https://doi.org/10.1186/s13037-020-00248-4

69. Tong M, Jiang Y, Xia D, Xiong Y, Zheng Q, Chen F, Zou L, Xiao W, Zhu Y (2020) Elevated expression of serum endothelial cell adhesion molecules in COVID-19 patients. J Infect Dis 222:894-898. https://doi.org/10.1093/infdis/jiaa349

70. Banskota AH, Stefanova R, Gallant P, McGinn PJ (2013) Monoand digalactosyldiacylglycerols: potent nitric oxide inhibitors from the marine microalga Nannochloropsis granulata. J Appl Phycol 25:349-357. https://doi.org/10.1007/s10811-012-9869-2

71. De Los RC, Ortega MJ, Rodríguez-Luna A, Talero E, Motilva V, Zubía E (2016) Molecular characterization and anti-inflammatory activity of galactosylglycerides and galactosylceramides from the microalga Isochrysis galbana. J Agric Food Chem 64:8783-8794. https://doi.org/10.1021/acs.jafc.6b03931

72. Lauritano C, Helland K, Riccio G, Andersen JH, Ianora A, Hansen EH (2020) Lysophosphatidylcholines and chlorophyllderived molecules from the diatom Cylindrotheca closterium with anti-inflammatory activity. Mar Drugs 18:1-11

73. Yasukawa K, Akihisa T, Kanno H, Kaminaga T, Izumida M, Sakoh T, Tamura T, Takido M (1996) Inhibitory effects of sterols isolated from Chlorella vulgaris on 12-O-tetradecanoylphorbol13-acetate-induced inflammation and tumor promotion in mouse skin. Biol Pharm Bull 19:573-576. https://doi.org/10.3390/ md18030166

74. Caroprese M, Albenzio M, Ciliberti MG, Francavilla M, Sevi A (2012) A mixture of phytosterols from Dunaliella tertiolecta affects proliferation of peripheral blood mononuclear cells and cytokine production in sheep. Vet Immunol Immunopathol 150:27-35. https://doi.org/10.1016/j.vetimm.2012.08.002

75. Davinelli S, Nielsen ME, Scapagnini G (2018) Astaxanthin in skin health, repair, and disease: a comprehensive review. Nutrients 10:1-12. https://doi.org/10.3390/nu10040522

76. Ng QX, De Deyn MLZQ, Loke W, Foo NX, Chan HW, Yeo WS (2020) Effects of astaxanthin supplementation on skin health: a systematic review of clinical studies. J Diet Suppl 10:1-14. https://doi.org/10.1080/19390211.2020.1739187

77. Su J, Guo K, Huang M, Liu Y, Zhang J, Sun L, Li D, Pang KL, Wang G, Chen L, Liu Z, Chen Y, Chen Q, Huang L (2019) Fucoxanthin, a marine xanthophyll isolated from Conticribra weissflogii ND-8: preventive anti-inflammatory effect in a mouse model of sepsis. Front Pharmacol 10:1-17. https://doi.org/10. 3389/fphar.2019.00906

78. Saide A, Lauritano C, Ianora A (2020) Pheophorbide A: state of the art. Mar Drugs 18:1-13. https://doi.org/10.3390/md18050257
79. Zhong Q, Wei B, Wang S, Ke S, Chen J, Zhang H, Wang H (2019) The antioxidant activity of polysaccharides derived from marine organisms: an overview. Mar Drugs 17:1-34. https://doi. org/10.3390/md17120674

80. Sansone C, Galasso C, Orefice I, Nuzzo G, Luongo E, Cutignano A, Romano G, Brunet C, Fontana A, Esposito F, Ianora A (2017) The green microalga Tetraselmis suecica reduces oxidative stress and induces repairing mechanisms in human cells. Sci Rep 7:1-12. https://doi.org/10.1038/srep41215

81. Casola A (2014) Respiratory viral infections and subversion of cellular antioxidant defenses. J Pharmacogenom Pharmacoproteom 5:1-19. https://doi.org/10.4172/2153-0645.1000141

82. Tanriverdi LH, Parlakpinar H, Ozhan O, Ermis N, Polat A, Vardi N, Tanbek K, Yildiz A, Acet A (2017) Inhibition of NADPH oxidase by apocynin promotes myocardial antioxidant response and prevents isoproterenol-induced myocardial oxidative stress in rats. Free Radic Res 51:772-786. https://doi.org/10.1080/10715 762.2017.1375486

83. Li S, Ren X, Wang Y, Hu J, Wu H, Song S, Yan C (2020) Fucoxanthin alleviates palmitate-induced inflammation in RAW 264.7 cells through improving lipid metabolism and attenuating mitochondrial dysfunction. Food Funct 11:3361-3370. https://doi. org/10.1039/d0fo00442a

84. Kim SH, Lim JW, Kim H (2018) Astaxanthin inhibits mitochondrial dysfunction and interleukin-8 expression in Helicobacter pylori-infected gastric epithelial cells. Nutrients 10:1-17. https:// doi.org/10.3390/nu10091320

85. Prybylski N, Toucheteau C, El Alaoui H, Bridiau N, Maugard T, Abdelkafi S, Fendri I, Delattre C, Dubessay P, Pierre G, Michaud P (2020) Bioactive polysaccharides from microalgae. Handb Microalgae-Based Process Prod. https://doi.org/10.1016/b9780-12-818536-0.00020-8

86. Zhang J, Liu L, Ren Y, Chen F (2019) Characterization of exopolysaccharides produced by microalgae with antitumor activity on human colon cancer cells. Int J Biol Macromol 128:761-767. https://doi.org/10.1016/j.ijbiomac.2019.02.009

87. Bafana A (2013) Characterization and optimization of production of exopolysaccharide from Chlamydomonas reinhardtii. Carbohydr Polym 95:746-752. https://doi.org/10.1016/j.carbpol.2013. 02.016

88. Chen B, You W, Huang J, Yu Y, Chen W (2010) Isolation and antioxidant property of the extracellular polysaccharide from Rhodella reticulata. World J Microbiol Biotechnol 26:833-840. https://doi.org/10.1007/s11274-009-0240-y

89. Sun Y, Wang H, Guo G, Pu Y, Yan B (2014) The isolation and antioxidant activity of polysaccharides from the marine microalgae Isochrysis galbana. Carbohydr Polym 113:22-31. https:// doi.org/10.1016/j.carbpol.2014.06.058

90. Ben HM, Ben IM, Garrab M, Aly R, Gagnon J, Naghmouchi K (2017) Antimicrobial, antioxidant, cytotoxic and anticholinesterase activities of water-soluble polysaccharides extracted from microalgae Isochrysis galbana and Nannochloropsis oculata. J Serbian Chem Soc 82:509-522. https://doi.org/10.2298/JSC16 1016036B

91. Fimbres-Olivarria D, Carvajal-Millan E, Lopez-Elias JA, Martinez-Robinson KG, Miranda-Baeza A, Martinez-Cordova LR, Enriquez-Ocaña F, Valdez-Holguin JE (2018) Chemical characterization and antioxidant activity of sulfated polysaccharides from Navicula sp. Food Hydrocoll 75:229-236. https://doi.org/ 10.1016/j.foodhyd.2017.08.002

92. Hooper PL (2020) COVID-19 and heme oxygenase: novel insight into the disease and potential therapies (Cell Stress and Chaperones, (2020), DOI: 10.1007/s12192-020-011269). Cell Stress Chaperones 25:1-11. https://doi.org/10.1007/ s12192-020-01130-Z 
93. Lekshmi V, Arun RA, Muraleedhara KG (2019) Sulfated polysaccharides from the edible marine algae Padina tetrastromatica attenuates isoproterenol-induced oxidative damage via activation of PI3K/Akt/Nrf2 signaling pathway - an in vitro and in vivo approach. Chem Biol Interact 308:258-268. https://doi.org/10. 1016/j.cbi.2019.05.044

94. Cardoso C, Pereira H, Franca J, Matos J, Monteiro I, PousãoFerreira P, Gomes A, Barreira L, Varela J, Neng N, Nogueira JM, Afonso C, Bandarra NM (2020) Lipid composition and some bioactivities of 3 newly isolated microalgae (Tetraselmis sp. IMP3, Tetraselmis sp. CTP4, and Skeletonema sp.). Aquac Int 28:711-727. https://doi.org/10.1007/s10499-019-00489-w

95. Haoujar I, Cacciola F, Abrini J, Mangraviti D, Giu D, Oulad Y, Majdoub E, Kounnoun A, Miceli N, Taviano MF, Mondello L, Rigano F, Senhaji NS (2019) The contribution of carotenoids, phenolic compounds, and flavonoids to the antioxidative properties of marine microalgae isolated from Mediterranean Morocco. Molecules 24:1-17. https://doi.org/10.3390/molecules24224037

96. Jerez-Martel I, García-Poza S, Rodríguez-Martel G, Rico M, Afonso-Olivares C, Gómez-Pinchetti JL (2017) Phenolic profile and antioxidant activity of crude extracts from microalgae and cyanobacteria strains. J Food Qual 2017:1-8. https://doi.org/10. $1155 / 2017 / 2924508$
97. Naoi M, Wu Y, Shamoto-Nagai M, Maruyama W (2019) Mitochondria in neuroprotection by phytochemicals: bioactive polyphenols modulate mitochondrial apoptosis system, function and structure. Int J Mol Sci 20:1-31. https://doi.org/10.3390/ijms2 0102451

98. Park GT, Go RE, Lee HM, Lee GA, Kim CW, Seo JW, Hong WK, Choi KC, Hwang KA (2017) Potential anti-proliferative and immunomodulatory effects of marine microalgal exopolysaccharide on various human cancer cells and lymphocytes in vitro. Mar Biotechnol 19:136-146. https://doi.org/10.1007/ s10126-017-9735-y

99. Lam JH, Baumgarth N (2019) The multifaceted B cell response to influenza virus. J Immunol 202:351-359. https://doi.org/10. 4049/jimmunol.1801208

100. Lai HL, Yang LC, Lin PT, Lai SY, Wang MY (2020) Phagocytosis activity of three sulfated polysaccharides purified from a marine diatom cultured in a semi-continuous system. Int J Biol Macromol 155:951-960. https://doi.org/10.1016/j.ijbiomac.2019. 11.054

Publisher's Note Springer Nature remains neutral with regard to jurisdictional claims in published maps and institutional affiliations. 